\title{
FABRICS OF IDENTITY: UNIFORMS, GENDER AND ASSOCIATIONS IN THE CAMEROON GRASSFIELDS
}

\author{
Jude Fokwang
}

In early March 2010, I phoned the president of a community-based association known as the Chosen Sisters to wish them well for the impending International Women's Day celebration. I was also curious to learn about the arrangements, if any, they had made in preparation for this day, which over the years has become a major holiday for most Cameroonian women. 'We decided not to design a new uniform this time,' she said, her voice vibrant and excited. 'The economic crisis seems to have affected most of our members particularly hard this year, so the association has resolved not to add any further burden on members.' This burden, it turned out, was the financial cost borne by members each time a new outfit had to be designed. Once every two years or so, the Chosen Sisters, like many associations in the Grassfields and elsewhere, design a new outfit, generally referred to as a 'uniform' in this part of the country. In its thirteen-year history, the Chosen Sisters have procured and retired over half a dozen uniforms. Uniforms are a serious affair in many associations, and many associations hold elaborate public functions to celebrate the unveiling of a new uniform (see Figure 1). For some, an association without a uniform is akin to an organization without an identity.

Having grown up in the Cameroon Grassfields, I realize how easy it is to take for granted the growing popularity of uniforms in Cameroon and the Cameroonian diaspora. ${ }^{1}$ As an object of intellectual curiosity, I was first struck by this phenomenon in March 2005 while carrying out ethnographic fieldwork on young people's associations in Bamenda, Cameroon. I was attending the International Women's Day, an unofficial holiday that has gained enormous prestige and significance in Cameroon in the last two decades. I arrived at Commercial Avenue, the city's most famous business district, where arrangements had been made for the Women's Day parade. Hundreds and hundreds of women's associations, dressed in the most colourful and elegant dresses, filed past the ceremonial ground, each armed with placards carrying a variety of messages relating to women's issues. While some of the associations were dressed in the official fabric endorsed by the Ministry of Women's Affairs, most of the groups proudly wore a distinctive uniform made of fabric of their choice. Elsewhere in the country, particularly in

JUDE FoKWANG is Assistant Professor of Anthropology in the Department of Sociology, Regis University, Denver. He is the author of Mediating Legitimacy: chieftaincy and democratisation in two African chiefdoms (2009). He is a member of the international editorial board of Anthropology Southern Africa. His research interests include indigenous modes of governance in Africa, youth politics, development and voluntary associations, and most recently he has initiated a project on material culture in the Cameroon Grasslands. Email: fokwang@gmail.com

${ }^{1}$ It is beyond the purview of this paper to provide a social history of the uniform in Cameroon. It is my hope that this paper will spur interest on this fascinating topic and perhaps generate further historical explorations that will culminate in a genealogy of uniforms.

(C) International African Institute 2015 


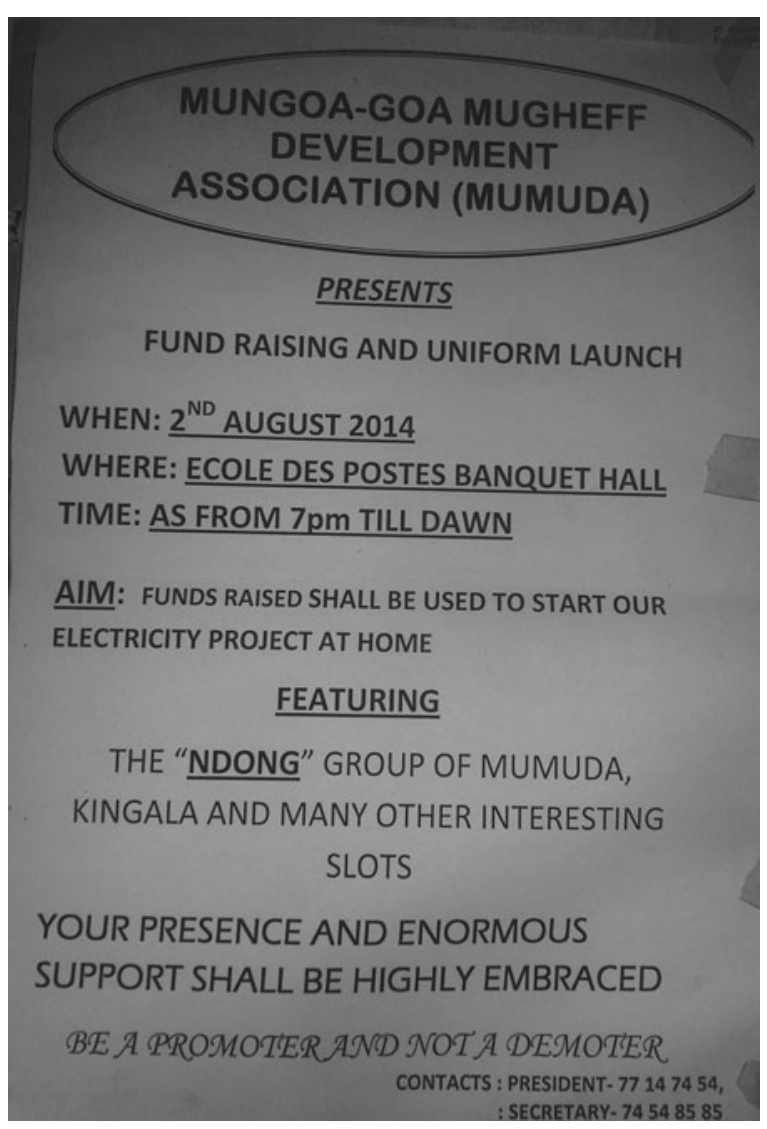

FIGURE 1 A Yaoundé-based association invites the public to the launch of its uniform.

the capital city, Yaoundé, associations could partake in the Women's Day parade only if they had designed their outfits from the official fabric approved by the ministry (see Pommerolle and Ngaméni, this issue), but people in Bamenda in 2005 were far less inclined to obey authority. ${ }^{2}$

In Cameroon, the late twentieth century, right through to the contemporary era, has been progressively marked by the uniformization of socio-cultural life,

\footnotetext{
${ }^{2}$ Citizens of Bamenda tend to take pride in resisting the central government, generally perceived to be Francophone-dominated. Such acts of resistance reveal themselves not only in wide-scale street protests witnessed during the struggle for political liberalization in the 1990s, but also in petty acts such as the refusal to adopt a government-sanctioned fabric for Women's Day. It is also instructive to point out that the North West Region of Cameroon and the city of Bamenda, its capital, remain the stronghold of the country's leading opposition party, the Social Democratic Front (SDF). Citizens from this part of the country have a history of getting away with things that may not generally sit well with the authorities in Yaoundé.
} 
championed in part by the masses, but particularly so by community-based associations such as the Chosen Sisters. By uniformization, I am referring to the ways in which uniforms have become ubiquitous not just as a cultural trend, but, more importantly, as social artefacts that lend themselves to a variety of interpretive schemes. Church associations, alumni or ex-student organizations, ethnic associations, professional and family groups have embraced the powerful allure of uniforms. Also known as aso ebi (a term of Yoruba origin, which translates as 'family uniform'), uniforms have gradually become a staple at weddings, funerals and 'death celebrations'. ${ }^{3}$ Their widespread popularity has crystallized as a new kind of orthodoxy adhered to by most citizens.

This paper considers why, in the last two decades, the obsession with uniforms has become so deeply entrenched in the Cameroon Grassfields and elsewhere, and why individuals and groups, particularly community-based associations, have played such a leading role in the proliferation of uniforms. If indeed the uniform is understood as a system of normatively prescribed communication (Joseph 1986: 86), then what sorts of meaning can we elicit from the wide-scale use of uniforms by individuals and groups in the Cameroon Grassfields? What meanings are embedded in uniforms and how are these shaped by gender, ethnic identity, age and other markers of social status? This paper is a preliminary attempt to find answers to some of these questions. It is also intended to inspire further ethnographic studies on uniforms that will result in broader analytical contributions in a very important but much neglected domain of scholarship on the Grassfields.

If clothing is a system of signs (Joseph 1986: 1), the uniform is of sociological interest because of its collective character, lending credence to its Latin origin uniformis, which means having one form or shape - and its embeddedness in bureaucratic structures that depict specialized offices, hierarchical positions, internal organizational relationships and external relationships with the public more accurately than any other types of clothing (Joseph 1986: 2). Although uniforms are often associated with the army, educational institutions, the healthcare industry and the police corps, uniforms as conceived in the Grassfields are more democratized in the sense that they belong to all kinds of organizations, informal as well as formal. Thus, Joseph's definition of the uniform as 'the legitimating emblem of membership within an organization' (Joseph 1986: 2) is useful to characterize the people's use of wax print cloth in the Grassfields and in Cameroon at large.

I focus on two associations whose use of uniforms has been particularly salient albeit for different reasons. I draw on fieldwork and secondary sources to demonstrate the ubiquity of uniforms in contemporary Grassfields society, and indeed throughout Cameroon. These associations set the stage for my later analysis in which I explore the multivocality of the uniform: the way uniforms stand for many objects, activities and relationships (Turner 1962: 42). Wax print uniforms serve as powerful symbols that convey a variety of cultural meanings. Beyond what wearers say about their outfits, their use reveals much about the society's evolving value system. I conclude by demonstrating the salience of uniforms as

\footnotetext{
${ }^{3}$ Commemorative ritual feast held by lineage members after the burial of an adult lineage member or to mark the first anniversary of such a member's passing.
} 
a special type of object, not only as markers of collective identity but also because they at once express the paradox of similarity and difference.

\section{THE MODERN ORIGINS OF UNIFORMS}

By the end of the fifteenth century, European textiles had infiltrated the West African market and over time were adapted to African consumption patterns by the companies that marketed them (Sylvanus 2007: 207; see also Röschenthaler, this issue). Nina Sylvanus's study shows how wax fabric produced in Europe became 'African', engendered by 'complex processes of localization in which this [European] fabric was inserted into a set of local practices and cultural strategies that allowed for its assimilation within African consumption structures' (Sylvanus 2007: 209). In contemporary West Africa, wax fabric, especially Dutchproduced wax prints, is especially popular. 'Most women,' Sylvanus recounts, 'desire to possess the greatest amount of wax fabric not only to demonstrate their good taste, but also to identify the person socially' (ibid.: 211). Furthermore, the wax print, as an object of high value, has inserted itself into the gift exchange systems of many West African cultures. This is particularly evident in the exchange of bridewealth (see, for example, Etienne 1977) and in the case of the Buhaya of Tanzania, where gifts of cloth of various kinds are necessary for the recognition of customary marriage (Weiss 1996: 142).

Historical records reveal that coastal women in West Africa played a leading role at the end of the nineteenth century as intermediaries between the coast and the hinterlands, marketing wax print fabrics and other European goods on behalf of European trading companies (Sylvanus 2007: 209). Women reportedly were at the forefront in promoting wax prints across regions, which eventually led to the entrenchment of these fabrics in the moral economies of gift exchange and popular consumption. Many have pointed to the 1970s as the period that saw the gradual appropriation of uniforms in socio-cultural life, bolstered in part by the booming oil economy, meaning that a substantial number of people could afford the imported fabrics that were easily converted into uniforms. ${ }^{4}$ The Grassfields' proximity to Eastern Nigeria also meant a steady flow of affordable fabrics, enabling the establishment of a cultural tradition of uniforms, which even the onset of the economic crisis in the mid-1980s failed to undermine. By the mid-1980s and the 1990s, uniforms had already become embedded in social life thanks to their popularity among women, the top consumers of wax print fabrics. Thus it is not surprising to note that women are the largest consumers of fabrics in Cameroon and across West Africa. In some localities, a woman's worth is measured by both the quantity and quality of the wax print fabrics she has accumulated over the years - most of them purchased by her husband or as gifts from family and friends. Men, however, are also involved, as suppliers, providers and consumers - the latter especially in the form of uniforms, which often serve as markers of their memberships in various communal associations. The fact that men and women have become profoundly implicated in the economy of the

\footnotetext{
${ }^{4}$ Michael Jindra, personal communication.
} 
uniform makes it a 'collective behaviour ... something enforced, a morality, an institution' (Baudrillard 1998: 81).

Women's and men's involvement in the economy of the uniform qualifies it as a 'collective behaviour', but in contrasting ways. Seniority tends to be indexed by the sartorial differences between young women and older married women. In the 1980s and earlier, older married women generally wore their wax prints in the form of a 'wrapper', which was tied around their waist and folded to secure it. Wrappers were generally accompanied by a blouse and a headscarf made from the same fabric as the wrapper. Young women, particularly unmarried women, patterned their outfits based on designs replicated from Nigerian fashion posters, catalogues and popular fashion magazines. Smith's (2010) observations about young women's dress patterns in south-eastern Nigeria is largely true of young Cameroonian women as well:

It is often quite easy in southeastern Nigeria to know whether a young woman is married simply by observing her manner of dressing. Sartorially, single women, particularly in urban settings, tend to dress in more liberal and sexually provocative outfits, which fit tightly to reveal the shape of breasts and buttocks and often show significant amounts of bare skin. (Smith 2010: 139)

Older and married women are generally more conservative in their dress patterns and their uniforms tend to be predominantly three-pieced: wrapper, blouse and headscarf. Young women, on the other hand, have no limits in terms of the designs their outfits may take because they incorporate fashionable patterns inspired by local and transnational influences.

Men's sartorial preferences are comparatively limited. Unlike young women, men's consumption of wax print fabrics is mostly in the form of uniforms. The majority of men's outfits generally take one of three forms: a jumper, shirt or agbadathe latter is a distinct type of long gown popular in Nigeria and northern Cameroon. Sometimes, the agbada is accompanied by a hat, sewn from the same type of fabric, rendering the wearer a completely uniformed subject. Most men's uniforms, however, are designed simply as shirts or jumpers, worn as a top with trousers of a matching colour.

Since the 1990s, Cameroonian social life - particularly that of the Grassfields has become increasingly uniformized; this has been due in part to the exponential surge in the number of associations that emerged in the wake of political liberalization. ${ }^{5}$ These were key vectors for the widespread adoption of uniforms. ${ }^{6}$ Associations have become strategic sites for the (re)production of everyday life,

\footnotetext{
${ }^{5}$ By political liberalization, I am referring to the wave of reforms that ensued following sustained protests and calls for democratic reforms by members of civil society after over two decades of one-party and authoritarian rule.

${ }^{6}$ Political parties have also played a significant role in the widespread adoption of uniforms: each party has adopted a particular fabric from which its members are expected to design their uniforms. Cameroon has over 200 registered political parties, which translates into a major boom for fabric manufacturers, particularly CICAM, a government-owned company charged with the production of wax prints for domestic consumption. CICAM also produces the official wax fabric for International Women's Day for the Central African Republic and Chad (see Pommerolle and Ngaméni, this issue).
} 
made evident by the multiple memberships to which the average Cameroonian devotes him- or herself.

\section{UNIFORMS, IDENTITY AND GENDERED ENCOUNTERS}

When I started researching the Chosen Sisters in the spring of 2005, I found that this was among the hundreds of women's groups that had participated in the 8 March parade in Bamenda wearing their bright navy blue wax print uniforms. A couple of weeks afterwards, I found myself attending the weekly Wednesday meeting of the Chosen Sisters, and I continued to do so for the next twelve months.

The Chosen Sisters was founded in 1999 by a group of sixteen young women from different ethnic and socio-economic backgrounds. Its primary objectives were to mobilize young women in the community for projects on self-reliance and to revitalize women's sense of dignity and moral renewal in a community disparaged for its sordid reputation. When I first began to research this group, its membership consisted of young women between the ages of twenty and thirtyeight; today, many of its members are in their forties. Its membership has fluctuated over the years, partly due to death and migration. Despite this, the Chosen Sisters remains one of the leading associations in Old Town, Bamenda, and it continues to attract members from outside the community. As a modern women's association with middle-class aspirations, it has inspired the formation of several women-only associations, such as the United Sisters, whose activities I have detailed elsewhere (Fokwang 2008).

At the end of my fieldwork in April 2006, the Chosen Sisters organized an elaborate farewell party in my honour despite the resistance I had mounted against the idea. On the chosen evening, many of the people I had interacted with over the months showed up in their uniforms - the same ones they had donned at the 8 March parade the previous year and in March 2006 (see Figure 2). This event was the culmination of my long observation of the centrality of the uniform in the affairs of this admirable group of women. During my fieldwork with the Chosen Sisters, I accompanied them to important community events, including 'death celebrations', 'born house'7 functions, seminars and many wakes, as well as the traditional Wednesday evening sessions. Group norms required that members should attend specific functions wearing a dedicated uniform from their growing collection of wax prints. Remarkably, the prestige or importance of a given event was generally matched by the type of uniform assigned for such an event. The most prestigious functions turned out to be those at which their Women's Day uniform was chosen - a revelation that made me feel very honoured when they wore it to my farewell party.

Earlier in the year, as members of the Chosen Sisters prepared for the International Women's Day, the association's president delivered an announcement that addressed the centrality of the uniform in the association. She declared that the executive had decided against procuring a new uniform for the

\footnotetext{
7'Born houses' are ritual events organized by women to celebrate the birth of a new child into a family. It is marked by the gifting of baby products such as soap, boxed detergents and wash basins. In return, the men provide drinks and plantains, the ritual food of choice.
} 


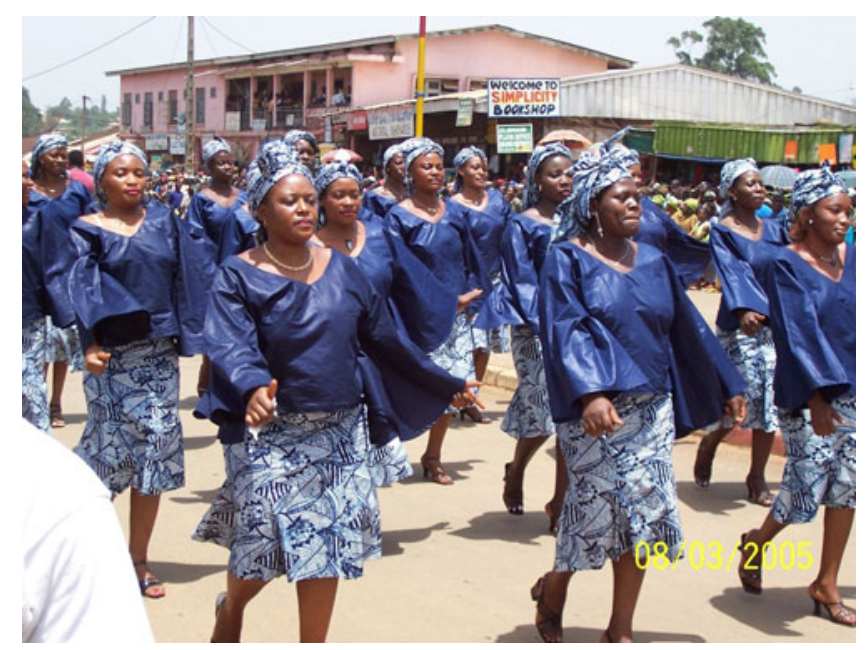

FIGURE 2 Members of the Chosen Sisters of Old Town participate in the Women's Day parade.

forthcoming Women's Day, unlike in previous years. Since 2000, the association had obtained a new uniform for each Women's Day event, but this time, the president insisted, focus should be devoted to the theme for that year. 'We will wear the same uniform we used last year,' she stated. The president and her executive had arrived at this decision with the intention of addressing popular criticisms that Women's Day had become an excuse for women to spend lavishly on new clothes, food and drinks, with little or scant regard for the intellectual expectations that ought to be devoted to the specified theme.

The uniform is central to the Chosen Sisters in two distinctive ways: as a mechanism of control and as an index of their collective but distinctive identity. Let us begin with the latter. The uniform, as seen earlier, may be easily understood as a legitimating emblem of membership within an organization. Thus, it is a key element in the construction of group identity and careful consideration is given to the symbols or traits that should be communicated. For the Chosen Sisters, the uniform is an outward sign or expression of the inner values they hold deeply. Central among these values is the idiom of kinship, as illustrated in the association's name and articulated most powerfully by the founding president:

You know, you can't choose your biological sisters. They are born into your family. You have no choice or control over this and whether you like it or not, they remain your sisters. But we wanted to choose people we could deal with. We wanted people whom we could trust and work with, people who were passionate about similar concerns. These issues made us call our association Chosen Sisters because we finally could exercise the right to choose our social sisters.

The right to choose one's sisters was further strengthened by the adoption of the same fabric in the design of formal outfits for the association. This is akin to the concept of 'one-kind' (pidgin English for matching clothes), which I will examine 
later. Other ethnographers have observed similar phenomena. Deborah Durham notes of Herero youth in Mahalapye, Botswana that 'close friends often construct identical dresses, or at least use the same fabric' as expressions of their shared sympathies and tastes (1999: 190). For the Chosen Sisters, the uniform symbolizes the bonds of sisterhood they have freely entered into. As individuals drawn from varying backgrounds but united in their conviction of a shared ethos, the uniform serves as an eraser of difference and alterity and at once stitches together the threads of solidarity that reinforce their sameness. The multiplicity of uniforms owned by members of the association also serves to distinguish their group from other associations. The association invests considerable time and resources to research the market and the community before adopting a particular fabric. The Chosen Sisters would not wish to be conflated with any other group at a public function because their fabric was somehow similar, or even identical, to another association's uniform.

As a mechanism of control, the uniform is closely associated with bureaucratic structures - institutions such as the military, the police force and educational institutions (particularly boarding schools), where students are compelled to wear uniforms throughout the academic year. For the Chosen Sisters, a set of moral norms is associated with their uniforms, two of which are particularly significant. Article 2 of the Chosen Sisters' constitution stipulates a series of prohibited behaviours accompanied by fines. These transgressions range from disorderly conduct at meetings to participating in activities that tarnish the association's reputation. One of the six violations listed in this section is the offence of wearing the association's uniform outside mandated associational activities; for this, the maximum fine of 1,000 FCFA (US\$2) is applicable. Furthermore, so potent is the uniform as an emblem among the Chosen Sisters that when a member is dismissed from the association, she is expected to surrender her uniforms. In this vein, the uniform serves as a certificate of legitimacy through which the relationship between the wearer and the organization is negotiated. By observing the norms with regard to the use of the association's uniforms, members demonstrate both their desire to respect the group's ethos and expectations (Joseph 1986: 67) and their recognition that deviation from these may culminate in expulsion.

The uniform also emerged as an item of preoccupation among members of the Ntambag Brothers Association (NBA), for reasons entirely different from those of the Chosen Sisters or other female organizations in the community. Founded in July 2004, the NBA is an exclusive male association of young men aged between twenty-five and thirty-nine in the community of Old Town, Bamenda. Like the Chosen Sisters, the NBA's membership has fluctuated over the years and currently stands at thirty-eight. When I began my fieldwork in this community, members of the NBA were exclusively young men with varying levels of education and diverse socio-economic backgrounds. Although most of them had attended secondary school and a few had completed university studies, most still lived with their parents or relatives and just a handful of them were employed in the formal economic sector. Youth unemployment, especially among young men, remains a major challenge in Cameroon and particularly so in Old Town, Bamenda. Since 2008, a handful of the NBA's members have migrated to Europe and the USA but still retain their membership through the payment of the required annual membership fee. The NBA operates a Facebook page through which members are updated about the association's activities. These 
days, the NBA delights in representing itself as a development-oriented organization; indeed, it has initiated the process of acquiring non-governmental organization (NGO) status in Cameroon. Unlike the Chosen Sisters, the NBA has undergone tremendous transformation in terms of its objectives. Initially, the group was founded as a male-only organization charged with coordinating the leisure activities of young men in the community. However, the group's objectives quickly transformed into organizing hygiene campaigns, developing a scholarship programme for underprivileged children, and establishing itself as a trusted liaison between the community of Old Town and the then Bamenda Urban Council (BUC). Ultimately, the NBA seeks to revitalize a sense of citizenship and belonging in the local society by spearheading community development projects.

Unlike the Chosen Sisters, who sought to improve their members' well-being, the NBA progressively positioned itself as oriented towards the development of the community. One way in which this became manifest was in the NBA leadership's refusal to adopt a uniform for the association despite repeated appeals in favour of it by some members. In fact, the NBA leadership equated uniforms with femininity, as they attempted to build an organization that was qualitatively and ideologically distinct from women's associations in the community. Each time the issue of uniforms was raised at Sunday meetings, opponents would appeal to members' sense of obligation towards the underprivileged children who, without the association's financial support, would not be enrolled in school. ${ }^{8}$ In this regard, members of the NBA sought to portray themselves as 'providers' rather than consumers - a theme to which I will return. However, the ambiguity or contradiction in this ideological position needs to be highlighted. Even though the leadership of the NBA opposed the appropriation of uniforms in their association, many of them owned wax fabric uniforms as members of either church choirs or ethnic associations.

Besides positioning themselves as providers, members of the NBA derided the concept of uniforms as a further strategy in forging a distinct identity for the association. Although I had listened to several negative remarks about uniforms during the early stages of my fieldwork, an incident in the summer of 2005 made this issue particularly evident. The Loving Sisters, a women's association outside Old Town, had invited the NBA to the formal launch of the association's uniform; this event was intended to introduce and raise funds for the nascent association. Prior to the launch, the Loving Sisters had attended mass at St Joseph's Cathedral, during which their uniforms were blessed by the presiding priest. At their customary Sunday meeting following the event, one of the NBA members who had attended the launch ridiculed the raison d'être of the Loving Sisters' uniform. 'What have these women accomplished that gives them the right to launch a uniform? Why should they launch a uniform at this time after only six months of the association's existence? It seems they're in a rush to nowhere but isn't it the same with all the other women's associations in our community?' Someone else wanted to know how and where funds had been obtained to sponsor such an elaborate party, including the cost of the bundles of fabric from which their uniforms had been designed. Ibrahim, the lone Muslim NBA

\footnotetext{
${ }^{8}$ Other activities prevalent in the women's associations, such as a monthly communal meal, a credit rotation scheme popularly known as njangi, and so on, were all rejected by the NBA.
} 
member, who sat near the door, quipped, 'Their boyfriends provided them with the money for the uniforms. They didn't buy anything themselves - that's why we're their boyfriends,' to which the rest of the group burst out laughing. For the NBA leadership and other opponents of the uniform in the association, resisting the adoption of a uniform implied a rejection of the feminization of their space. Such a discourse or pattern of action echoes the much critiqued aspects of the early anthropological studies of masculinity, which not only emphasized the centrality of male-female relations but tended to define masculinity as anything that women were not (Gutmann 1997: 386). For the NBA, the rejection of the uniform translates to a definition of masculinity as being anything other than the traits that define female associations, especially the privileged position of the uniform in such associations.

What else might be at play in the NBA's rejection of the uniform and its deliberate characterization as an object of femininity? Nathan Joseph suggests two possible answers with respect to uniforms in general: one is the conflict between two organizations, each with its distinctive set of symbols, and each vying for control of the master status. A second possibility is the attempt of a group to preserve its monopoly over symbols and status in the face of attempts at control by an intervening group (Joseph 1986: 87). Neither of these reasons is adequate in explaining the relationship between the Chosen Sisters and the NBA. However, it seems likely that the NBA's reluctance to embrace the powerful allure of the uniform serves two particular purposes: firstly, to legitimate its status as a development-focused organization; and secondly, to promote a view of the association as holding a higher moral ground in the community - which Joseph refers to as 'vying for control of the master status'.

It is evident by now that associational life in Old Town, Bamenda is a highly gendered affair. This has worked remarkably in favour of the community's womenfolk, who have tapped into the powerful resource of women's associations to empower themselves and advocate for women's dignity and rights. In fact, this reconfiguration of the gender order has positioned women as important social actors in the community of Old Town. Changes in gender relations in Bamenda are reminiscent of other ethnographers' observations elsewhere in the Grassfields. Goheen (1995; 1996), for instance, notes that women in both rural and urban areas of Nso' are devising new ways to control the fruits of their economic activities, thus altering a longstanding pattern that had favoured patriarchy. Contrary to ethnographic representations of women elsewhere in precolonial Africa as powerful and equal to their male counterparts, Goheen shows that women in Nso' occupied the lower rungs of a gender-stratified society - men controlled any surplus value produced by women (Goheen 1995: 74). Young and older men in the Grassfields have responded to these changes by drawing on new symbols and narratives to seek control of the master status (cf. Fuh 2012), and the NBA's opposition to uniforms, however trivial, could be understood along these lines. Notwithstanding this argument, the uniform has become a powerful symbol through which specific kinds of identities are represented, constituted, articulated and contested.

Despite the NBA's opposition to the adoption of a uniform, its members remain deeply implicated in the uniform economy. As boyfriends, brothers and fathers, many of them wanted to be identified as providers and caretakers of the community, including their womenfolk, while labelling the Chosen Sisters and other 
female associations as mere 'consumers' of wax print fabrics. Richard Waller's (2006) concept of productive masculinity associated with the world of work and responsible citizenship captures one of the ways in which young men in the NBA viewed themselves. Productive masculinity refers to the kind of masculinity predicated on a man's ability to work, provide for his family and ensure the general welfare of his family and kin group or community. Even though the NBA leadership and many members were publicly opposed to the adoption of a uniform for the association, most of them confided to me during interviews and informal conversations that they had bought dresses as well as wax print fabrics for their girlfriends (some of which had been used as uniforms). By contributing partially or wholly to the purchase of outfits and fabrics for their girlfriends, young men saw themselves as investing in their women's beauty, thus affirming their position as providers. Some ethnographers have frowned upon the simplistic representation of women's bodies as an index of men's wealth (Popenoe 2004), but young men in Old Town insist on this perspective in order to validate themselves as co-involved in the splendour and stylishness of their women. But this isn't the whole story. Seen from another vantage point, members of the NBA as individuals are inevitably implicated in a structure of exchange that they hope will reinforce their individual positioning as productive men. While the Chosen Sisters are proud owners of many uniforms, the NBA has constructed an identity founded on the negation of that which they define as distinctly feminine - the uniform. Men's assertion of masculinity is therefore contradicted by their indirect implication in the process of consumption. Although few of them would agree, they are arguably consumers implicated in a process that may be understood as a kind of social labour. Consumption, Baudrillard reminds us, is social labour precisely because the consumer is required and mobilized as a worker in the consumption process (Baudrillard 1988: 84). Even though the consumer may think of his or her effort as personal, it does in fact bear all the traces of social (collective) responsibility.

\section{THE POLITICAL AND SOCIAL CHARACTER OF UNIFORMS}

Although uniforms have tended to be associated with bureaucratic structures, I have demonstrated in the preceding paragraphs the ways in which local associations have appropriated the uniform and subjected it to a range of discursive uses. In what follows, I will analyse the uniformization of social and political life by exploring further the ways in which uniforms are intertwined with political mobilization and the sociality of everyday life, and by demonstrating the dispersal and wide-scale appropriation of uniformed clothing among ordinary people and the political elite.

Ethnographers have documented the invented tradition of uniforms as special objects in Africa, and particularly so in the Cameroon Grassfields. During German colonial rule in the Grassfields, for instance, officials often made presents of German military regalia to selected chiefs as tokens of alliance. King Njoya of Bamun reportedly received shipments of uniform parts such as helmets and breastplates for his soldiers (Geary 1996: 173). Geary observes further that these traditional rulers tended to use the uniforms to their advantage in the 
local competition for power by intimidating their rivals with the potent visual symbols of their German allies. In precolonial Nigeria, richly embroidered robes, which were often the preserve of the political elite, were gifted to individuals as a reward for particular deeds or to solidify patron-client relationships (Renne 2004: 128). Uniform clothing also served to express local, gendered and historical identities in colonial Namibia, specifically among the Herero, for whom formal organized bodies known as 'flags' carried significant political import (Hendrickson 1996). Each flag organization was associated with a particular colour and its members met once or twice a year to visit the burial sites of their heroes. Although these flag organizations were similar in many ways (like the female associations in Old Town), they differed in their allegiance to particular heroes, ultimately symbolized by the colour of their flag from which their uniforms were tailored.

The political considerations of clothing, and uniforms in particular, have also been examined in postcolonial contexts. Elisha Renne contends that: 'Dress associated with particular local and national forms of government in Nigeria, specifically khaki uniforms and agbada or riga, has been used to communicate a range of polyvalent political messages' (Renne 2004: 137). These messages include the changing forms of political order - military rule, traditional rule and democratic rule - as well as the social distinctions between royalty and commoners, military and civilians, educated elite and non-literates.

The uniformization of associational life as seen in the women's groups in Old Town or in the flag organizations in colonial Namibia shows that the standardization of clothing patterns is often a source of group-imposed conformity (Joseph 1986: 68), and tends to be employed by states and nationalist movements to unify disparate groups, thereby assuming coercive proportions. This necessitates a brief commentary on the role of political party uniforms in Cameroon.

When the Cameroon People's Democratic Movement (CPDM) was launched in 1985 to replace the defunct Cameroon National Union (CNU), a set of brand-new party uniforms was introduced to grace the new political dispensation. Like the Herero flag organizations described by Hendrickson, the new CPDM uniforms were designed in two distinct colours to organize the different genders: blue for women and brown for men. ${ }^{9}$ Inscribed on both versions of the uniform were the party motto, a tongue of fire and the image of a relatively youthful president Biya. ${ }^{10}$ This same fabric has been in circulation for the last twenty-eight years of Biya's thirty-one-year rule. Although over eighty, Biya's image on the uniform has not aged since it was originally printed, perhaps a reminder to Cameroonians of his eternal youthfulness and enduring vitality irrespective of his biological age. ${ }^{11}$ Like rulers elsewhere (see Röschenthaler, this issue), Biya himself has hardly been seen in the CPDM party uniform even during presidential campaigns, whereas his ministers and party officials often dress in CPDM uniforms for most political and even supposedly non-partisan functions. Stories also abound

\footnotetext{
${ }^{9} \mathrm{~A}$ pink version was later introduced for the women's uniform in addition to the blue.

${ }^{10}$ At the time of his accession to power, Biya was in his early fifties. Over eighty in 2014 , he is yet to reveal any plans to step down. See also Pommerolle and Ngaméni, this issue.

${ }^{11}$ Biya successfully overturned constitutional limits to the presidency in 2008 , calling it an undemocratic attempt to stifle the people's choice.
} 
in the public press of ministers who distribute CPDM party uniforms to members in their constituencies in a show of state patronage. ${ }^{12}$

The uniformization of socio-cultural life is also deeply embedded in everyday processes and at specific ritual events such as family meetings, weddings, funerals, 'death celebrations' and the reunions of religious or professional associations. Local chiefdoms celebrate annual royal dance festivals or commemorate the end of a ritual calendar year, such as the Lela festival (cf. Fardon 2006). But one particular period stands out in the ritual calendar of the Grassfields: the December-January period characterized by the festivities of Christmas and New Year celebrations. Christmas is at the heart of various mobilizations of symbolic and material resources, of which clothing is the most salient, and it is closely associated with the concept of Christmas clothes - usually a set of brand-new clothes bought by a family head. For most children and housewives, the ultimate source of anxiety is the absence or outright refusal of the family head to provide them with Christmas clothes. Members of the middle class and the wealthy tend to buy designer clothes, which are known in pidgin English as ready-made clothes or boutique. For households with a modest income, the most cost-effective strategy is to purchase a bundle of wax print from which several dresses are designed; this results in a 'family uniform', or what is referred to by the pidgin expression of one-kind or, more recently, aso ebi (Yoruba for family uniform). The family uniform or Christmas clothes, made using a single fabric, serve as a social boundary that defines the borders of the kin group in relation to non-kin.

The uniform is thus multivocal in every sense. While it may betray the shallowness of one's pocket in particular contexts, it is often appropriated to symbolize affection and harmony between individuals and groups. At most funerals and death celebrations in the present-day Grassfields, the bereaved family is easily distinguishable by their one-kind or aso ebi, which not only separates them visually from the rest of the participants but also demonstrates to the public and their ancestors (the living-dead) that the family is unified and strong, particularly if ancestral blessings are sought for the lineage's continued production and reproduction (Jindra 2011).

It has also become customary for married couples, irrespective of their social class, to attend public and private functions dressed in a common fabric, although styled differently. While this has become quite fashionable for many, both young and old, the common fabric in this case embodies and expresses the affection and love between them, epitomized by their display of a uniform appearance - which in other circumstances communicates distinction.

\section{UNIFORMS AND THE PARADOX OF SIMILARITY AND DIFFERENCE}

Drawing on the ethnographic narratives presented above, I will proceed to argue that uniforms are significant as objects of anthropological analysis precisely

\footnotetext{
${ }^{12}$ See, for example, 'Ama Muna distributes uniform to Momo CPDM', 19 June 2010, <http:// the-news-from-cameroon.com/article.php?category_id=25\&article_id=1604>, accessed 17 November 2012. According to this news story, Miss Muna, Cameroon's Culture Minister, distributed uniforms allegedly bought by the elites of the North West in Yaoundé for distribution to various organs of the party in preparation for Paul Biya's visit to the region.
} 
because of their unique role as markers of collective identity, but also because they embody and simultaneously express the paradox of similarity and difference. This perspective builds on and extends Nathan Joseph's (1986) seminal work on uniforms, in which he contends not only that uniforms may be understood as a form of communication but - and even more importantly - that uniforms help us to better understand the nature of nonconformity (Joseph 1986: 86) and difference. It is evident by now that uniforms, as part of a broad configuration of symbols, play a decisive role in negotiating gender identities in the contemporary Grassfields, especially in the community of Old Town, Bamenda. In this vein, the uniform may be understood as a living archive in two specific ways: as a deposit and expression of the material culture of associational life; and as a special 'social skin' through which the interplay of similarity and difference is mediated. Terence Turner's notion of the 'social skin' may be mined further to analyse the interplay between social identity and uniforms. Bodily adornment, Turner reminds us, conveys the idea that a given individual may be covered in a 'fabric of cultural meaning' even without clothing (Turner 1980: 115). Central to this 'fabric of cultural meaning' is the body, which is not merely a biological or psychological entity but 'the frontier of the social self as well' (Turner 1980: 112). In other words, the human body is the 'common frontier of society' and serves as the 'symbolic stage upon which the drama of socialisation is enacted' (Turner 1980: 112). Clothing and other forms of bodily adornment (modification) constitute key aspects of this drama of socialization. These dramas and their meanings have been the basis of most scholarly work on cloth and clothing (Hansen 2004; Schneider and Weiner 1986; Schneider 1987; 2006; Etienne 1977; Pancake 1992; Cooper 1993; Weiner 1989; Weiss 1996) and, to a lesser extent, on uniforms.

The uniform may be understood as a special type of social skin for two overlapping reasons: its communal character and its role as a principal agent in the construction and communication of collective identification, of which associational groups represent its fullest expression. As a social skin, the uniform serves as a powerful 'symbolic stage' upon which the drama of collective identity is constructed, circulated and contested.

In order to unpack the foregoing claim, a brief explanation of 'collective identity' is warranted. Richard Jenkins (1996) suggests that common sense generally distinguishes between individual and collective identity, but these two identities cannot be studied in isolation. This is because the individual and the collective are entangled with each other; individual and collective identifications become explicit as a result of interaction; the processes by which each is produced and reproduced are analogous; and, lastly, the theorization of identification must therefore accommodate the individual and the collective in equal measure (Jenkins 1996: 16). A distinction between identity and identification is necessary in order to develop my interpretation further. Identification refers to "the ways in which individuals and collectivities are distinguished in their social relations with other individuals and collectivities'. Identity 'is a matter of knowing who's who ... [that is] ... the systematic establishment and signification, between individuals, between collectivities, and between individuals and collectivities, of relationships of similarity and difference' (Jenkins 1996: 16). While individual identity emphasizes difference, collective identity emphasizes similarity. The uniform, I argue, plays a pivotal role in the constitution and expression of collective identity because of its emphasis on similarity: that is, it functions as a group emblem to which all valid members must defer. 
Let us return once again to the Chosen Sisters. For its members, the uniform represents the fullest expression of the ideology of kinship that legitimates the group's nomenclature and existence. In fact, this line of reasoning is true of the other female associations in Old Town and beyond, whereby the uniform emerges as the ultimate eraser of their multiple identities in favour of a single ideological identity - sisters by choice. According to this logic, the absence of a uniform may undermine the quest for a unified and uniform identity, which may partly explain the Loving Sisters' so-called haste to launch a uniform even if this was derided by members of the NBA.

While the uniform, like other forms of clothing, conceals our bodies, it also reveals a variety of things about us - for instance, our identity (geographical or historical), economic status, and much more (Barnes and Eicher 1992: 1). Thus, for associations such as the Chosen Sisters, their repertoire of uniforms equally aims to communicate distinction and the values dear to them as modern women aspiring to middle-class status. If identity is really a matter of knowing who's who, and involves systematic establishment and signification between individuals, between collectivities, and between individuals and collectivities, then taken as a whole, each association, kin group or user of the uniform seeks to establish a distinct identity that may not be conflated with that of another group. Hence, in adopting a new uniform, associations generally endeavour to find a wax print fabric that has not been adopted by any other organization. This is also the reason why wealthier associations or families opt to commission unique fabrics that carry distinctive symbols that relate to the group or its heroes. It is also in this sense that the uniform - a type of social skin - mediates between similarity and difference.

But the question may also be posed as to whether the uniform suppresses individuality or internal differences within associations, kin groups or any other formal or informal structure that uses it. One of the characteristics of the uniform, Joseph argues, is that it stifles individuality: that is, 'individual idiosyncrasies of behaviour, appearance, and sometimes physical attributes' (Joseph 1986: 68). Schneider and Weiner (1986) echo this view when they assert that, as much as clothing conceals, uniforms also tend to erase difference. By its very essence, the uniform entails some kind of communal dimension that may be deployed in a variety of ways by differentially positioned individuals and groups. However, ethnographers have been suspicious of the neutralizing qualities of the uniform. Writing about the flag organizations of the Herero in colonial Namibia, Hendrickson observes that:

Overall, the uniforms subsume any individual into a representation of the whole, while allowing for the recognition of individual achievements within the flags' standards of behavior and morality. Variation between uniforms from individual to individual is seen only in specific aspects of the design. Differences in men's and women's uniforms reflect differences in their everyday dress. (Hendrickson 1996: 218-19)

This observation is also evident in the Grassfields, where family groups' one-kind clothes or aso ebis are sewn to reflect the gendered differences of everyday dress. But even within women-only associations such as the Chosen Sisters, uniforms often provide scope for the expression of individual identity and, as a consequence, difference. Clothes, Hansen (2000) suggests, are not worn passively but require the active participation of the individual. While uniformity is generally evident in the 
adoption of a common fabric, members tend to be given the leeway to design outfits that communicate their specific tastes and preferences. This is apparent among members of the Chosen Sisters, who exhibit minor variations in their headscarves, neck patterns and other styles. This implies that the uniform is not entirely hegemonic in its quest to erase otherness. If anything, social actors may harness the multivocality of the uniform to communicate difference. Indeed, uniformization provides scope for the assertion of embodied individual identities that may rightly be perceived as an extension of the collective. In this vein, the body of a given member becomes the frontier of associational conviviality, if we accept that the 'human body is simultaneously a referent of individual continuity, an index of collective similarity and differentiation, and a canvas upon which identification can play' (Jenkins 1996: 19). Consequently, individual and collective identities are routinely entangled with each other and the uniform thus exemplifies the interplay of similarity and difference.

The uniform, in mediating the interplay of similarity and difference, also helps us to understand better the nature of nonconformity (Joseph 1986: 86). Studies of clothing in Africa and elsewhere have revealed the ways in which 'power is represented, constituted, articulated, and contested through dress' (Allman 2004). If we substitute dress with uniforms in the above quote, we can tap even deeper into the multivocality of uniforms in relation to collective identities. In what way does a critical survey of the uniform enhance our understanding of nonconformity? Take the NBA's objection to the adoption of a uniform as an emblem of group identity. Whereas the NBA has forged a masculinity predicated partly on the rejection of the uniform, this same object has been central to the articulation of sisterhood and collective identity among the Chosen Sisters and other associations. Perhaps, without the uniform, the NBA may have identified another symbol around which to define a distinct identity separate from the women's associations. However, in this particular ethnographic context, the uniform has served as the rallying point of resistance and nonconformity for members of the NBA who seek to elevate themselves to a higher moral and civic level as agents preoccupied with the material needs of their community, in contrast to the symbolic concerns of the Chosen Sisters and similar associations.

Nonconformity is also evident in the longstanding reluctance of women's groups in the North West Region to adopt the Women's Day uniform officially sanctioned by the Ministry of Women's Affairs. Until recently, women's associations in Bamenda took part in the Women's Day parades in their chosen uniforms, despite government executive orders that recommended the use of a single uniform throughout the country. In fact, nonconforming associations in Yaoundé were often barred from participating in the parades. The national government's preoccupation with official party or Women's Day uniforms reveals the extent to which Turner's 'social skin' could easily be upscaled to what one might call the 'political skin'. When an object such as the uniform becomes the source of state-imposed conformity, there is the possibility that resistance could be mounted by objecting to wearing it. For many years, this was the case with successive Women's Day uniforms in the Bamenda region. The local administration's enfeebled capacity to enforce the national government's directives not only was revealed through the nonconformity of many women's associations, but also confirmed the region's reputation as the stronghold of oppositional politics in the country. 


\section{CONCLUSION: UNIFORMIZATION AS A NEW KIND OF ORTHODOXY}

Uniformization describes the widespread and intensified domestication of wax fabrics in the Cameroon Grassfields and their incorporation into a complex chain of networks and meanings. For many who subscribe to the powerful allure of the uniform, it cannot be reduced simply to a bureaucratic affair but constitutes a 'public thing' whose multivocality is apparent in diverse settings and circumstances. The uniform's orthodoxy is qualified on the grounds that it has become embedded in everyday relations and practices beyond the ritual contexts of Christmas, death celebrations or weddings. For most associations, full membership and a distinct identity are established once a uniform is launched. By this token, the uniform has become critical to the representation and reproduction of Grassfields society and serves as a 'critical link between social groups across space and through time' (Hendrickson 1996: 8). Furthermore, the uniform holds a particularly privileged place in unravelling the salience of dress not only as an 'index of difference between social groups' (Hendrickson 1996: 14) but also as a powerful site for the articulation of collective identities.

For associations such as the Chosen Sisters, the uniform summarizes a range of values and aspirations dear to their heart, central among them the ideology of sisterhood. For them, the uniform symbolizes a distinct kin group, forged out of the diverse ethnic and socio-economic identities embodied by its members. It also mediates the interplay of similarity and difference within the group and between the association and others. For the NBA, the uniform enables its members to construct and articulate what Waller (2006) has referred to as productive masculinity, epitomized by their capacity to provide and channel their resources towards the underprivileged. Kin groups, couples and other types of informal organizations have also appropriated the uniform to celebrate and communicate communal conviviality.

While both individuals and informal groups have been captivated by the powerful allure of the uniform, what gives this phenomenon new sociological impetus is the role that community-based associations have played in the proliferation of uniforms. The post-1990 era has witnessed an exponential growth in the number of associations and interest groups, thanks in part to the liberalization of political space as well as to what Piot (2010) has referred to as the 'NGOization' of the West African landscape in the post-Cold War period. The opening up of the socio-political landscape was simultaneously marked by the emergence or explosion of 'powerful expressions of collective identity' (Castells 1997: 2), not necessarily challenging globalization but rather staking claims to cosmopolitan lifestyles and identities. ${ }^{13}$ Organizations such as the Chosen Sisters, the NBA and hundreds of others that populate the Bamenda urban landscape have come to define the new face of a vibrant and engaged citizenry, all of which has contributed to engraving the uniform as a new form of orthodoxy. Taken as a collective, these community-based associations constitute the 'symbolic stage' upon which the drama of uniformization is enacted. In these associations, members are socialized on the pivotal role of the uniform as an emblem of group identity and distinction.

${ }^{13}$ This is evidenced by the hundreds of formally registered associations in the city of Bamenda. 
Variously experienced as one-kind at Christmas, or the aso ebi employed by lineage members at family events and death celebrations, or the certificate of legitimacy and membership in formal associations, uniforms have tremendous anthropological import. The uniform is a special type of clothing: a multivocal symbol conveying a variety of activities and relationships. However, its fullest expressions can be analysed in the context of associational life, where the interplay of similarity and difference is dramatized. As a result, the wax print uniform has become a potent symbol complex mediating a diverse range of identities and processes in the Grassfields. It implicates both men and women in a system of extensive values and has become embedded in men's and women's everyday lives - even in situations of apparent resistance, as detailed in the peculiar case of the NBA. The NBA's rejection of the incorporation of wax print uniforms into associational life does not diminish the potent standing of the uniform as a multivocal symbol that mediates difference, similarity and, ultimately, collective identities.

\section{ACKNOWLEDGEMENTS}

An earlier version of this paper was presented at the African Studies Association annual conference in Philadelphia in November 2012 and benefited extensively from the comments of Silvia Forni, Peter Geschiere and Dominique Malaquais. My analysis also drew on discussions with fellow panellists Ute Röschenthaler and Marie Pommerolle. I would also like to express gratitude to three anonymous reviewers for their insightful queries on the original submission. Michael Jindra provided a thoughtful critique of my original argument, for which I am grateful.

\section{REFERENCES}

Allman, J. (2004) 'Fashioning Africa: power and the politics of dress' in J. Allman (ed.) Fashioning Africa: power and the politics of dress. Bloomington and Indianapolis IN: Indiana University Press.

Barnes, R. and J. B. Eicher (1992) 'Introduction' in R. Barnes and J. B. Eicher (eds) Dress and Gender: making and meaning. Providence RI and Oxford: Berg Publishers.

Baudrillard, J. (1998) The Consumer Society: myths and structures. London: Sage. Castells, M. (1997) The Power of Identity. Volume II. Oxford: Blackwell.

Cooper, B. M. (1993) 'Cloth, commodity production, and social capital: women in Maradi, Niger 1890-1989', African Economic History 21: 51-71.

Durham, D. (1999) 'The lady in the logo: tribal dress and Western culture in a Southern African community' in J. B. Eicher (ed.) Dress and Ethnicity: chance across space and time. Washington DC: Berg Press.

Etienne, M. (1977) 'Femmes et hommes, pagnes et colonisation: la transformation des relations de production et de distribution chez les Baule de Côte d'Ivoire', Cahiers d'études africaines 17: 41-64.

Fardon, R. (2006) Lela in Bali: history through ceremony in Cameroon. Oxford: Berghahn Books.

Fokwang, J. (2008) 'Youth subjectivities and associational life in Bamenda, Cameroon', Africa Development XXXIII: 157-62. 
Fuh, D. (2012) 'The prestige economy: veteran clubs and youngmen's competition in Bamenda, Cameroon', Urban Forum 23: 501-26.

Geary, C. M. (1996) 'Political dress: German-style military attire and colonial politics in Bamum' in I. Fowler and D. Zeitlyn (eds) African Crossroads: intersections between history and anthropology in Cameroon. Providence RI and Oxford: Berghahn Books.

Goheen, M. (1995) 'Gender and accumulation in Nso', Paideuma 41: 73-81.

Goheen, M. (1996) Men Own the Fields, Women Own the Crops: gender and power in the Cameroon Grassfields. Madison WI: University of Wisconsin Press.

Gutmann, M. C. (1997) 'Trafficking in men: the anthropology of masculinity', Annual Review of Anthropology 26: 385-409.

Hansen, K. T. (2000) Salaula: the world of secondhand clothing and Zambia. Chicago IL: University of Chicago Press.

Hansen, K. T. (2004) 'The world in dress: anthropological perspectives on clothing, fashion, and culture', Annual Review of Anthropology 33: 369-92.

Hendrickson, H. (1996) 'Bodies and flags: the representation of Herero identity in colonial Namibia' in H. Hendrickson (ed.) Clothing and Difference: embodied identities in colonial and post-colonial Africa. Durham NC and London: Duke University Press.

Jenkins, R. (1996) Social Identity. London and New York NY: Routledge.

Jindra, M. (2011) 'The rise of "death celebration" in the Cameroon Grassfields' in M. Jindra and J. Noret (eds) Funerals in Africa: explorations of a social phenomenon. New York NY and Oxford: Berghahn Books.

Joseph, N. (1986) Uniforms and Nonuniforms: communication through clothing. New York NY: Greenwood Press.

Pancake, C. M. (1992) 'Gender boundaries in the production of Guatemalan textiles' in R. Barnes and J. B. Eicher (eds) Dress and Gender: making and meaning. Oxford: Berg Publishers.

Piot, C. (2010) Nostalgia for the Future: West Africa after the Cold War. Chicago IL: University of Chicago Press.

Popenoe, R. (2004) Feeding Desire: fatness, beauty, and sexuality among a Saharan people. London and New York NY: Routledge.

Renne, E. P. (2004) 'From khaki to Agbada: dress and political transition in Nigeria' in J. Allman (ed.) Fashioning Africa: power and the politics of dress. Bloomington and Indianapolis IN: Indiana University Press.

Schneider, J. (1987) 'The anthropology of cloth', Annual Review of Anthropology 16: 409-48.

Schneider, J. (2006) 'Cloth and clothing' in C. Tilley, W. Keane, S. Kuechler et al. (eds) Handbook of Material Culture. London: Sage Publications.

Schneider, J. and A. B. Weiner (1986) 'Cloth and the organization of human experience', Current Anthropology 27: 178-84.

Smith, D. J. (2010) 'Promiscuous girls, good wives, and cheating husbands: gender inequality, transitions to marriage, and infidelity in Southeastern Nigeria', Anthropological Quarterly 83: 123-52.

Sylvanus, N. (2007) 'The fabric of Africanity: tracing the global threads of authenticity', Anthropological Theory 7: 201-16.

Turner, T. S. (1980) 'The social skin' in J. Cherfas and R. Lewin (eds) Not Work Alone: a cross-cultural view of activities superfluous to survival. Beverly Hills CA: Sage Publications. 
Turner, V. W. (1962) 'Themes in the symbolism of Ndembu hunting ritual', Anthropological Quarterly 35: 37-57.

Waller, R. (2006) 'Rebellious youth in colonial Africa', Journal of African History 47: 77-92.

Weiner, A. B. (1989) 'Why cloth? Wealth, gender and power in Oceania' in A. B. Weiner and J. Schneider (eds) Cloth and Human Experience. Washington DC and London: Smithsonian Institution Press.

Weiss, B. (1996) 'Dressing at death: clothing, time, and memory in Buhaya, Tanzania' in H. Hendrickson (ed.) Clothing and Difference: embodied identities in colonial and post-colonial Africa. Durham NC and London: Duke University Press.

\section{ABSTRACT}

This paper argues that the uniform, conceived as a special type of 'social skin', has been incorporated by individuals and groups into a complex chain of processes and meanings in the Cameroon Grassfields; I describe this practice as the uniformization of socio-cultural life. I demonstrate that uniforms, unlike ordinary clothing, are salient precisely because of their unique role as markers of collective identity but also because they embody and simultaneously express the paradox of similarity and difference. Central to these processes and construction of meaning are community-based associations that have elevated the uniform to a new kind of orthodoxy. These perspectives are borne out by ethnographic interpretations of the ways in which variously positioned subjects in the Grassfields relate to and embody the special object that the uniform represents.

\section{RÉSUMÉ}

Cet article soutient que l'uniforme, conçu comme un type spécial de «peau sociale », a été intégré par des particuliers et des groupes dans une chaîne complexe de processus et de sens dans les Grassfields du Cameroun ; l'auteur décrit cette pratique comme l'uniformisation de la vie socioculturelle. Il démontre que l'uniforme, contrairement au vêtement ordinaire, est important précisément de par son rôle unique de marqueur d'une identité collective, mais également parce qu'il incarne et exprime simultanément le paradoxe de similarité et de différence. Les associations communautaires sont au cœur de ces processus et de cette construction de sens, en ayant fait de l'uniforme un nouveau type d'orthodoxie. Ces perspectives s'appuient sur des interprétations ethnographiques de la manière dont des objets diversement positionnés dans les Grassfields se rapportent à l'objet spécial que représente l'uniforme, et l'incarnent. 